\title{
CITRIC ACID PRODUCTION FROM ORANGE PEEL WASTES BY SOLID-STATE FERMENTATION
}

\author{
Ana María Torrado ${ }^{1}$; Sandra Cortés ${ }^{1}$; José Manuel Salgado ${ }^{1}$; Belén Max ${ }^{1}$; Noelia Rodríguez ${ }^{1}$; Belinda P. Bibbins ${ }^{1}$; Attilio \\ Converti $^{2}$; José Manuel Domínguez ${ }^{1^{*}}$
}

${ }^{1}$ Departamento de Ingeniería Química. Universidad de Vigo (Campus Ourense), Edificio Politécnico. As Lagoas. 32004 Ourense, Spain; ${ }^{1}$ Laboratory of Agro-food Biotechnology, CITI-Tecnópole, Parque Tecnológico de Galicia, San Cibrao das Viñas, Ourense, Spain; ${ }^{2}$ Department of Chemical and Process Engineering, Genoa University, Via Opera Pia 15, 16145 Genoa, Italy.

Submitted: June 24, 2010; Returned to authors for corrections: September 24, 2010; Approved: November 03, 2010.

\begin{abstract}
Valencia orange (Citrus sinensis) peel was employed in this work as raw material for the production of citric acid (CA) by solid-state fermentation (SSF) of Aspergillus niger CECT-2090 (ATCC 9142, NRRL 599 ) in Erlenmeyer flasks. To investigate the effects of the main operating variables, the inoculum concentration was varied in the range $0.5 \cdot 10^{3}$ to $0.7 \cdot 10^{8}$ spores/g dry orange peel, the bed loading from 1.0 to $4.8 \mathrm{~g}$ of dry orange peel (corresponding to $35-80 \%$ of the total volume), and the moisture content between 50 and $100 \%$ of the maximum water retention capacity (MWRC) of the material. Moreover, additional experiments were done adding methanol or water in different proportions and ways. The optimal conditions for CA production revealed to be an inoculum of $0.5 \cdot 10^{6}$ spores/g dry orange peel, a bed loading of $1.0 \mathrm{~g}$ of dry orange peel, and a humidification pattern of $70 \% \mathrm{MWRC}$ at the beginning of the incubation with posterior addition of $0.12 \mathrm{~mL} \mathrm{H}_{2} \mathrm{O} / \mathrm{g}$ dry orange peel (corresponding to $3.3 \%$ of the MWRC) every 12 h starting from $62 \mathrm{~h}$. The addition of methanol was detrimental for the CA production. Under these conditions, the SSF ensured an effective specific production of CA (193 mg CA/g dry orange peel), corresponding to yields of product on total initial and consumed sugars (glucose, fructose and sucrose) of 376 and $383 \mathrm{mg} \mathrm{CA} / \mathrm{g}$, respectively. These results, which demonstrate the viability of the CA production by SSF from orange peel without addition of other nutrients, could be of interest to possible, future industrial applications.
\end{abstract}

Key words: Orange peel, citric acid, Aspergillus niger, solid-state fermentation

\section{INTRODUCTION}

Today, citrus is unrolling in almost all regions of the world inside the strip bounded by a line of latitude 40 degrees
$\mathrm{N}$ and $\mathrm{S}$. The citrus processing industry yearly generates tons of residues, including peel and segment membranes, from the extraction of citrus juice in industrial plants. The management of these wastes, which produce odor and soil pollution,

*Corresponding Author. Mailing address: Departamento de Ingeniería Química. Universidad de Vigo (Campus Ourense), Edificio Politécnico. As Lagoas. 32004 Ourense, Spain.; Tel.: (+34) 988387075 Fax: (+34) 988387 001.; E-mail: jmanuel@uvigo.es 
represents a major problem for the food industry (33). Orange peel contains soluble sugars and pectin as the main components. According to Rivas et al. (42), the orange peel is in fact constituted by soluble sugars, $16.9 \% \mathrm{wt}$; starch, $3.75 \%$ wt; fiber (cellulose, $9.21 \% \mathrm{wt}$; hemicelluloses, $10.5 \% \mathrm{wt}$; lignin $0.84 \% \mathrm{wt}$; and pectins, $42.5 \% \mathrm{wt}$ ), ashes, $3.50 \% \mathrm{wt}$; fats, $1.95 \% \mathrm{wt}$; and proteins, $6.50 \% \mathrm{wt}$.

The total sugar content of orange peel varies between 29 and $44 \%$ (21), soluble and insoluble carbohydrates being the most abundant and economically interesting constituents of this residue (26). Approximately $50 \%$ of the dry weight of orange is soluble in alcohol (47), and soluble sugars are the major components also of this fraction. Glucose, fructose and sucrose are the main sugars, although xylose can also be found in small quantities in orange peel. Insoluble polysaccharides in orange peel are composed of pectin, cellulose and hemicelluloses. Pectin and hemicelluloses are rich in galacturonic acid, arabinose and galactose, but they also contain small amounts of xylose, glucose, and perhaps rhamnose $(16,33)$. Glucose is the dominant sugar in the cellulosic fraction, which also contains some quantities of xylose and arabinose, traces of galactose and uronic acids, and in some instances mannose. On the other hand, lignin seems to be absent in these tissues. Consequently, a mixture of cellulases and pectinases is needed to complete the conversion of all polysaccharides to monosaccharides $(15,16)$.

Citric acid (CA), an intermediate of the tricarboxylic acid cycle, is found in a variety of acidic fruit juices, particularly in the citric ones, although its extraction from natural sources, primarily lemon, was gradually replaced by biological procedures, mainly based on the use of microfungi, which are currently the most widely used. The production of CA was described in 1893 by Wehmer as a result of the metabolism of the fungus Penicillium glaucum (49). In 1913, it was obtained the first patent in the United States for a method of producing CA by Aspergillus niger in sugar solutions. Recent estimates put the global production of $\mathrm{CA}$ in over 1.4 million tons per year (49) with rising trend in demand. More than $50 \%$ of this volume is being produced in China. It is traditionally used in the food industry thanks to its high solubility, extremely low toxicity, and palatability; moreover, examples are given of some recent $\mathrm{CA}$ applications in the industry of detergents and cosmetics, or as the active ingredient in some bathroom and kitchen cleaning solutions (56).

The low cost and the high carbohydrate content and susceptibility to fermentation make citrus byproducts attractive raw materials for CA biotechnological production (42). In most cases, the industrial production of CA by fermentation is done using $A$. niger strains, but also many other microorganisms are capable of accumulating CA, including other species belonging the same genus, Penicillium janthinellum, Penicillium restrictum, Trichoderma viride, Mucor pirifromis, Ustulina vulgaris and various species of the genera Botrytis, Ascochyta, Absidia, Talaromyces, Acremonium and Eupenicillium (25). There are some processes that use various species of yeast (mainly belonging to the genus Candida) or bacteria and a wide range of carbon sources, including sucrose, glucose, molasses, alcohol, fatty acids, natural oils, acetate, and hydrocarbons (4). Additionally, some attempts have been made to induce CA overproduction by mutations of different microorganisms, particularly A. niger strains $(31,46)$. Aravantinos-Zafiris et al. (5) examined three different strains of $A$. niger and found that the strain NRRL 599 was the best CA producer, followed by NRRL 364 and NRRL 567, respectively.

CA has been successfully produced using submerged, liquid surface or solid state fermentation (SSF), with the best results being obtained in this last case (36). In spite the SSF was the first process proposed for the production of CA using different absorbing materials (beet pulp, sugar cane bagasse, pineapple pulp) with embedded solutions of carbohydrates (mainly sucrose-rich solutions), CA has been conventionally produced by submerged fermentation, mainly by A. niger. However, because of several advantages over the submerged fermentations such as solid waste management, biomass energy 
conservation, production of high value products and little risk of bacterial contamination (44), the SSF methods have recently gained attention using agroresidues like sugarcane or cassava bagasse $(29,30,38,46)$, carob pod (44), areca husk (36), beet molasses (1), soy residues (27), sugar cane bagasse, coffee husk and cassava bagasse (55) and waste of food processing industries including pineapple wastes $(6,11,18,22,52,53)$, apple pomace $(20,48)$, grape pomace (19), or different fruit peels, including kiwi (17), orange (43) or prickly pear (12).

The main characteristics of SSF that differentiate it from submerged cultures are the low water content, which is usually related to low values of water activity, especially for hydrophylic supports, and the enhanced aeration. The $\mathrm{O}_{2}$ and $\mathrm{CO}_{2}$ exchange between the gas phase and the substrate depends on the intra- and inter-particle mass transfer in SSF systems, which is influenced by various factors $(8,14)$ : a) the matrix porosity that depends on its physical characteristics and water content; b) the pore size and particle diameter that influence the area of interchange; c) the system geometry; and d) the aeration and the agitation, especially when the fermentation is advanced.

Following a previous study (42), where the bioproduction of CA by A. niger NRRL 599 was studied in submerged culture using a medium prepared after sugars solubilization by orange peel autohydrolysis, in this work we investigated the potential of such a residue as a substrate for CA production by solidstate fermentation by the same microorganism. To this purpose, we investigated the effects of inoculum concentration, bed loading, and water and methanol addition on CA production and culture performance. In comparison to other related works, no nutrients were added to the fermentation broth in order to minimize the costs of production. Finally, the results of CA production by SSF were compared with those previously obtained in submerged culture.

\section{MATERIALS AND METHODS}

\section{Raw material}

Samples of Valencia orange (Citrus sinensis) peel obtained from a national citrus processing plant were dried at $40{ }^{\circ} \mathrm{C}$ to reach a final moisture lower than $10 \%$, milled to a particle size less than $2 \mathrm{~mm}$, homogenized in a single lot to avoid any variation in composition, and stored at $4{ }^{\circ} \mathrm{C}$ in a cold chamber until use.

\section{Microorganism}

Aspergillus niger CECT-2090 (ATCC 9142, NRRL 599), obtained from the Spanish Collection of Type Cultures (Valencia, Spain), was used in this work.

\section{Inoculum}

The fungus was grown on slants of potato dextrose agar (Scharlau Chemie, Barcelona, Spain) at $33{ }^{\circ} \mathrm{C}$ for 5 days. A spore inoculum was prepared by adding sterile distilled water to the slant, shaking vigorously for $1 \mathrm{~min}$ with the help of sterile glass balls to prepare the spore suspension, and filtering to eliminate mycelium particles. Spores were quantified by optical density measurement at $750 \mathrm{~nm}$ using a calibration curve.

\section{Maximum water retention capacity}

Before SSF, an experiment was carried out in triplicate to determine the maximum water retention capacity (MWRC) of the dry orange peel under saturated conditions, which resulted to be $3.6 \pm 0.1 \mathrm{~mL}$ of water absorbed per gram of dry material. This result was taken into account when the liquid phase was added to the substrate to promote the microbial growth.

\section{Culture media and sterilization}

Dried and milled samples of orange peel were dispensed into $50 \mathrm{~mL}$ Erlenmeyer flasks provided with aluminum caps with 24-26 mm diameter, model Sero-Tap (Selecta, Abrera, Spain), without any additional nutrients. Different bed loadings from 1.0 to $4.8 \mathrm{~g} /$ Erlenmeyer were assayed according to the experimental design described later, which corresponded to minimum and maximum loadings of 35 and $80 \%$ of the flask working volume, respectively. The material was moistened by 
two-step addition of the liquid phase. In a first step, and for all cases, $1.6 \mathrm{~mL}$ of water/g, corresponding to $45 \%$ of the MWRC, was added before sterilization to protect the material from thermal degradation. Then, the rest of water necessary to reach the level of moisture desired for each experiment was added together with the inoculum. Sterilization was made by autoclaving at $100^{\circ} \mathrm{C}$ for $1 \mathrm{~h}$.

\section{Incubation}

Flasks were incubated at $30{ }^{\circ} \mathrm{C}$ in a stationary incubator where a saturated $\mathrm{NaCl}$ solution allowed to maintain the level of air moisture needed to prevent drying of the material. Each flask was stirred every $24 \mathrm{~h}$ with a sterile spatula inside a laminar flow chamber to reduce compactation and diffusion restrictions. All experiments were done in triplicate.

In selected experiments performed with variable degrees of humidification, sterile distilled water was added at different rates and proportions, as indicated in Table 1. For the study of the effect of methanol on citric acid production, experiments were done adding methanol at the beginning of the cultivation at variable proportions $(0,2,4$, and $6 \% \mathrm{v} / \mathrm{w})$. Methanol, of analytical grade, was purchased from Sigma (Switzerland). In both cases, the content of each flask was shaken by a sterile spatula after every addition.

\section{Sampling}

The whole content of a flask was used for each sample. The material was homogenized carefully with the help of a spatula or even of a mortar, especially when the abundant cell growth hampered the homogenization of the samples. Amounts of about $0.5-1.0 \mathrm{~g}$ were used to determine the moisture content in oven at $105{ }^{\circ} \mathrm{C}$. According to the sample consistency, aqueous extracts were obtained from the remaining sample by addition of distilled water up to a 10:1 (v/w) ratio. The extraction was assisted mechanically with an Ultra-Turrax homogenizer, model T25 (IKA-Labortechnik, Staufen, Germany) for $30 \mathrm{~s}$, and centrifugation at 8,000 rpm for $10 \mathrm{~min}$ to eliminate the solid particles.

\section{Analytical methods}

Samples of the aqueous extracts were filtered through 0.45 $\mu \mathrm{m}$-pore membranes and assayed for glucose, fructose, sucrose, citric acid, and galacturonic acid concentrations by HPLC, model 1100 (Agilent, Palo Alto, CA) with a Refractive Index detector. Standards were prepared from the corresponding reagents purchased from Sigma (Switzerland). Separation was performed using a ION-300 column (Transgenomic Inc., San Jose, CA), thermostated at $50{ }^{\circ} \mathrm{C}$ and eluted with $0.01 \mathrm{M} \mathrm{H}_{2} \mathrm{SO}_{4}$ at $0.4 \mathrm{~mL} / \mathrm{min}$ flow rate. All analyses were carried out in triplicate, and the error was less than $3 \%$.

Total sugars (including neutral and acid sugars) were analyzed by the method of Dubois et al., modified according to Strickland and Parsons (51), which is based on the phenolsulfuric acid reaction that allows determining the reducing sugars after acid hydrolysis of polysaccharides. Glucose, from Sigma (Switzerland), was used as a standard.

\section{Experimental design}

The effect of the bead loading and water content on orange peel SSF was studied by means of a second-order rotatable experimental design with $\alpha=1.414$ and five replicates in the center of the domain, according to Akhnazarova and Kafarov (2) and Box et al. (7). Experimental domain and coding criteria are given in Table 2. The significance of the coefficients of the models was calculated using Student's t test $(\alpha<0.05)$ as the acceptance criterion. Model consistency was verified by Fisher's $F$ test $(\alpha<0.05)$ applied to the following mean square (QM) ratios:

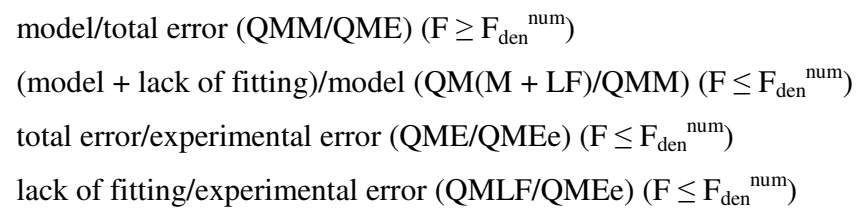


Table 1. Conditions of SSF with variable water addition.

\begin{tabular}{ccccccc}
\hline Runs & $\begin{array}{c}\text { Amount added } \\
\text { in each addition } \\
\text { (mL/g) }\end{array}$ & $\begin{array}{c}\text { Frequency of } \\
\text { addition (h) }\end{array}$ & $\begin{array}{c}\text { Time of } \\
\text { addition (h) }\end{array}$ & $\begin{array}{c}\text { Number of } \\
\text { additions }\end{array}$ & $\begin{array}{c}\text { mL water/g dry solid } \\
\text { accumulated at the } \\
\text { end of incubation }\end{array}$ & $\begin{array}{c}\text { increase of \% } \\
\text { saturation at the } \\
\text { end of incubation }\end{array}$ \\
\hline A (control) & 0 & 0 & 0 & 0 & 0 & 0 \\
B & 0.08 & 12 & 48 & 6 & 0.48 & 13.3 \\
C & 0.12 & 12 & 48 & 6 & 0.72 & 20.0 \\
D & 0.12 & 12 & 62 & 5 & 0.60 & 16.7 \\
\hline
\end{tabular}

Table 2. Experimental domain and codification of the independent variables analyzed by means of a second-order rotatable factorial design applied to citric acid production by SSF on orange peels.

\begin{tabular}{cccc}
\hline \multirow{2}{*}{ Coded values } & \multicolumn{3}{c}{ Actual values } \\
\cline { 2 - 4 } & $\begin{array}{c}\text { Water content } \\
\text { (\% of saturation) }\end{array}$ & $\begin{array}{c}\text { Water content } \\
(\mathbf{m L} / \mathbf{g} \text { dry solid })\end{array}$ & $\begin{array}{c}\text { Bed loading } \\
\text { (g/flask) }\end{array}$ \\
\hline$-1.414(-\alpha)$ & 50.0 & 1.80 & 1.0 \\
-1 & 57.3 & 2.06 & 1.6 \\
0 & 75.0 & 2.70 & 2.9 \\
+1 & 92.7 & 3.34 & 4.2 \\
$+1.414(+\alpha)$ & 100.0 & 3.60 & 4.8 \\
\hline
\end{tabular}

Codification: $V c=(V n-V o) / \Delta V n$. Decodification: $V n=V o+(\Delta V n \times V c)$. Vn, natural value; $V c$, coded value; Vo, natural value in the center of the domain; $\Delta \mathrm{Vn}$, increment of $\mathrm{Vn}$ corresponding to one unit of $\mathrm{Vc}$.

\section{RESULTS AND DISCUSSION}

\section{Preliminary experiments: inoculum concentration}

A preliminary set of solid-state fermentations was performed using orange peel as substrate and Aspergillus niger at different inoculum concentrations. The objective of these runs was to evaluate the suitability of this system for citric acid production and to get a first insight of the kinetics of this fungus on this substrate in view of future optimization of this production.

Considering the aeration requirements of this microorganism, a low bed loading of $2 \mathrm{~g}$ of dry orange peel (corresponding to $46.8 \%$ of the flask working volume) was selected as a condition of reduced depth of the matrix in the flask able to provide an aerobic environment suitable for cell growth. Taking into account that inoculum concentrations in the range $10^{3}-10^{8}$ spores/g substrate are usually employed for CA production by $A$. niger $(32,45)$ and that an increase in the inoculum level is well known to reduce the lag phase, three different spore concentrations were tested, namely $0.5 \cdot 10^{3}$, $0.5 \cdot 10^{6}$ and $0.7 \cdot 10^{8}$ spores/g dry orange peel, the last being the maximum value that could be easily achieved using the procedure described in Materials and Methods. The solid was moistened to reach $75 \%$ saturation, and incubations were done at $30^{\circ} \mathrm{C}$.

The results illustrated in Fig. 1 demonstrate the feasibility of using orange peel as a substrate for CA production by $A$. niger by SSF, with no need of supplying any additional nutrient and using the sterilization as the only pretreatment. Moreover, they clearly show that the intermediate inoculum level $\left(0.5 \cdot 10^{6}\right.$ spores/g of orange peel) ensured the highest product concentration (170.5 $\mathrm{mg}$ of $\mathrm{CA} / \mathrm{g}$ dry orange peel). 
It should be noted that the lag phase was very long at the lowest inoculum level $\left(0.5 \cdot 10^{3}\right.$ spores/g of dry orange peel). Both the consumption of sugars and the production of CA (Fig. 1) did in fact start no sooner than $60 \mathrm{~h}$. As a consequence, after $86 \mathrm{~h}$ the CA concentration was only $65 \mathrm{mg} / \mathrm{g}$ dry orange peel, and a large portion of sugars remained unconsumed in the medium. Also the highest inoculum level $\left(0.7 \cdot 10^{8}\right.$ spores/g dry orange peel), used with the aim of accelerating the fermentation, revealed to be unadvisable from an industrial point of view, owing not only to the long time required to produce $\mathrm{CA}$, but also to the final $\mathrm{CA}$ concentration reached (100.4 mg/g dry orange peel after $72 \mathrm{~h}$ ), which was considerably lower than that obtained at the intermediate inoculum level.

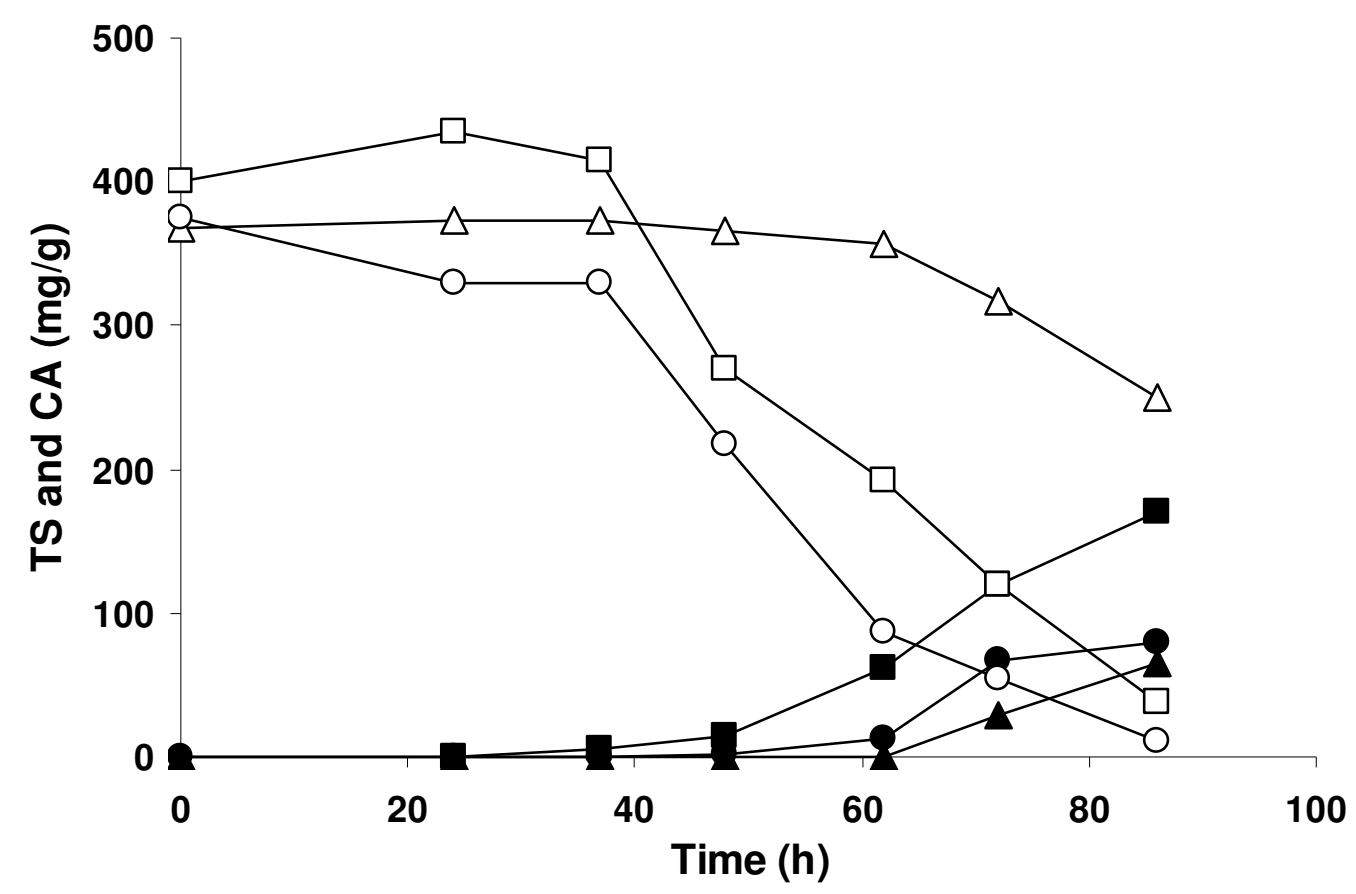

Figure 1. Effect of the inoculum concentration on CA production from orange peel by A. niger SSF. Inoculum concentration (spores/g dry orange peel): $0.5 \cdot 10^{3}(\boldsymbol{\Delta}), 0.5 \cdot 10^{6}(\boldsymbol{\bullet}), 0.5 \cdot 10^{8}(\bullet)$. Results are the average of three independent experiments. Standard deviations were below $2.2 \%$ of the mean.

In order to get a more detailed view of the kinetics, Fig. 2 illustrates the evolution of the solubilized sugars and CA production during the best run $\left(0.5 \cdot 10^{6}\right.$ spores/g of orange peel). It is noteworthy the occurrence of two distinct phases of the culture, determining a fermentation pattern quite different from the trophophase-idiophase one usually observed in submerged culture. A first phase, which occurred approximately between 23 and $47 \mathrm{~h}$, was characterized by a) a low rate of CA production coinciding with the disappearance of sucrose, b) an initial increase in glucose and fructose concentrations as the mainly result of sucrose hydrolysis at higher rate than its metabolization, and c) the net solubilization of sugars. A second one corresponded to an intense CA production and the net consumption of sugars.

In addition to sucrose, glucose and fructose, also pectins were analyzed since they are the main component of orange 
peel (42). Pectins are a heterogeneous group of acidic structural polysaccharides, consisting mainly of galacturonic acid units. There are many references describing the ability of this microorganism to produce pectinases that catalyze the partial or total hydrolysis of pectins, leading to their solubilization and the release of galacturonic acid. The production of pectinases is referenced either in solid-state or in submerged cultures $(34,50)$, and even in semisolid lemon pulp culture (10), which is similar to the orange peel SSF. It is also described the production of pectinolytic enzymes by A. niger even on materials with low pectin content including wheat bran and soy (9). Whereas the addition of sucrose, glucose, or galacturonic acid reduced the production of pectinases in submerged cultures, during SSF the addition of these sugars even increased their levels in the broth (50).

With the aim of evaluating the possible solubilization and hydrolysis of pectins from orange peel cultures, the concentration of total sugars (TS) was followed throughout the fermentation by the phenol-sulfuric method that allows quantifying neutral and acidic sugars from pectins together (Fig. 2). It can be observed that TS was actually higher than the sum of neutral sugars determined by HPLC. Such a difference became more evident at $48 \mathrm{~h}$, when TS achieved a maximum value coinciding with the beginning of the net consumption of glucose and fructose and the intensive production of CA, which suggests the occurrence of a significant solubilization of pectines. After $48 \mathrm{~h}$, TS decreased drastically together with the levels of neutral monosaccharides. Nevertheless, the rate of TS reduction was lower than that of neutral sugars, reflecting a gradual accumulation of pectins and/or their products of hydrolysis. According with that, galacturonic acid (GA) started to accumulate progressively in the medium coinciding with the increase of total sugars at $48 \mathrm{~h}$ and until the end of the culture. These data seem to provide an indirect confirmation of the ability of $A$. niger to produce pectinases in these conditions.

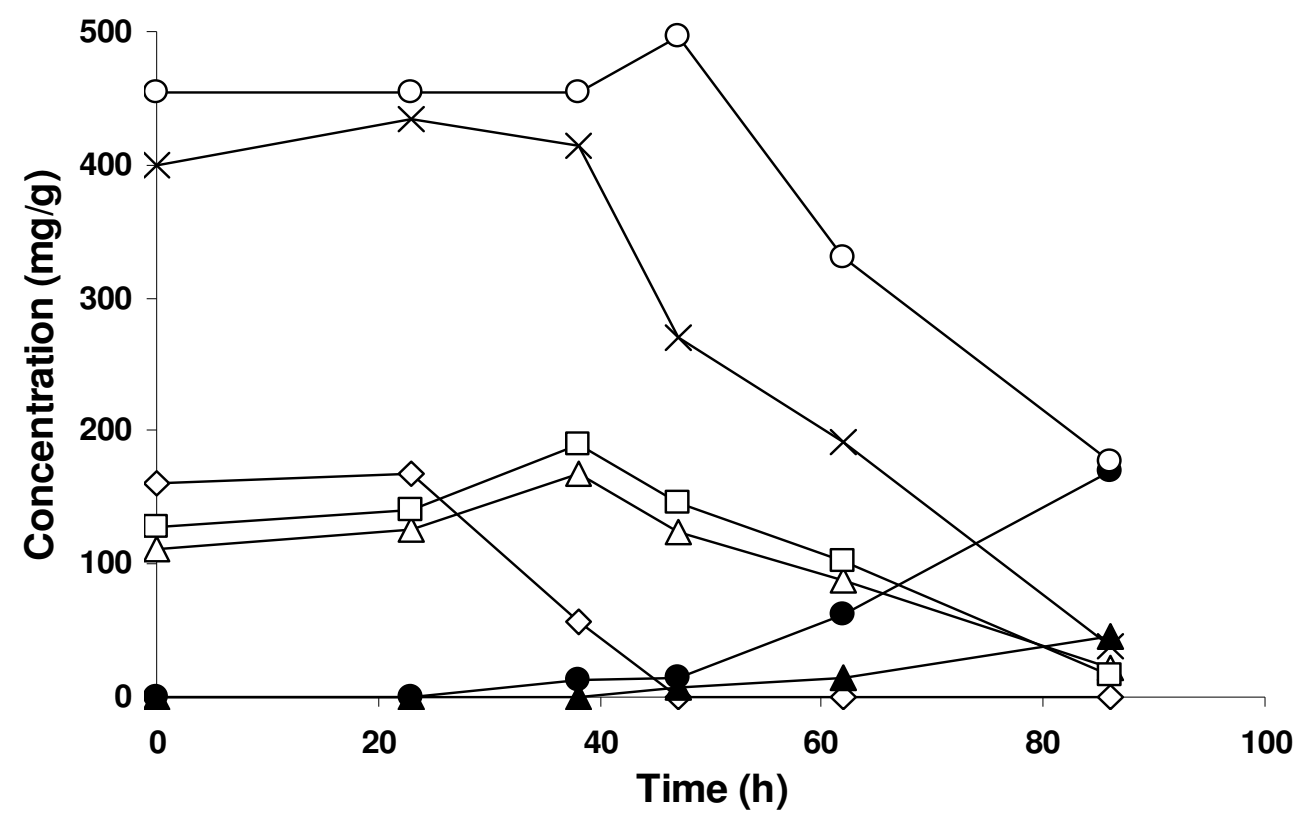

Figure 2. Time behavior of sugars consumption, CA production and galacturonic acid release during SSF of orange peel by $A$. niger using an inoculum concentration of $0.5 \cdot 10^{6}$ spores/g dry orange peel. Sucrose $(\diamond)$, glucose $(\Delta)$, fructose $(\square)$, sucrose + glucose + fructose $(\times)$, total sugars $(\circ)$, galacturonic acid $(\boldsymbol{\Delta})$, citric acid $(\bullet)$. Results are the average of three independent experiments. Standard deviations were below $2.4 \%$ of the mean. 
Finally, it must be highlighted the progressive acidification of the medium during these runs from about 4.5 to approximately 2.7 , as the consequence of CA accumulation. Although A. niger has higher tolerance to low $\mathrm{pH}$ than other microorganisms, excess acidification is well known to affect both growth and CA production. Rivas et al. (2) did in fact found an increase in the CA production from 4.9 to $8.3 \mathrm{~g} / \mathrm{L}$ when the $\mathrm{pH}$ was controlled by the addition of $\mathrm{CaCO}_{3}$ during the submerged culture of this microorganism. On the contrary, the control of $\mathrm{pH}$ during the SSF process is difficult; therefore, this variable was only monitored in this study.

CA yields achieved in SSF of fig fruits practically remained constant when initial $\mathrm{pH}$ values ranged from 4 to 8 (45), whereas Selvi et al. (46) found the best results in terms of $\mathrm{CA}$ yield using sugarcane bagasse as a substrate at initial $\mathrm{pH}$ of 4. Nevertheless, it has been reported that CA is accumulated in significant amounts only when the $\mathrm{pH}$ is below 2.5 (28). Although the reasons for the requirement of a low $\mathrm{pH}$ are not clear, it is known that at $\mathrm{pH}>4$ the gluconic acid produced by the reaction catalyzed by glucose oxidase accumulates at the expense of CA (40). Moreover, due to its extracellular localization, this enzyme is directly susceptible to the external $\mathrm{pH}$ and is inactivated at $\mathrm{pH}<3.5$ (57). On the basis of these considerations, we think that the low $\mathrm{pH}$ values reached in this work likely favored the CA production.

\section{Influence of the bed loading and water content}

The $\mathrm{O}_{2}$ supply is a limiting factor of submerged aerobic cultures because, due to its low solubility in water, its concentration in a saturated aqueous medium is usually lower than the microorganism requirements. This aspect is of a great concern for CA production because A. niger is an aerobic microorganism, and the oxygenation is essential for its growth (35). Although in SSF the oxygen availability is many orders of magnitude higher than that found in submerged cultivations, several reports demonstrated the importance of aeration also in SSF. For example, even though forced aeration at the beginning of the solid-state fermentation of Kumara by $A$. niger favored the CA production in a packed-bed reactor compared to flasks, too high air flow rates exerted adverse shear stress to the fungus (32). Vandenberghe et al. (55) reported that an air flow rate of $60 \mathrm{~mL} / \mathrm{min}$ improved cassava fermentation by A. niger, achieving $265 \mathrm{~g}$ citric acid/ $\mathrm{kg}$ dried cassava.

According to Lu et al. (32), the bed loading (B) is the most important factor affecting the CA production by SSF because it influences the degree of aeration in the system. It is also related to heat transfer, which is affected by higher restrictions in the solid state than in submerged cultures. Optimal B is therefore necessary to ensure the suited supply of oxygen and heat exchange necessary for efficient growth and CA production.

The water content $(\mathrm{W})$ of the medium is another important operating variable for CA production by SSF because it influences growth and metabolism of the microorganism as well as the mass transfer phenomena primarily related to the diffusion of nutrients, oxygen and toxic metabolites (41). In addition, it causes swelling of the substrate, facilitating the penetration of the mycelium for its effective utilization (39), and affects heat transfer since its molecules occupy the interparticular spaces and/or causes aggregation of the solid particles. Therefore, the optimal moisture content depends on the specific requirements of the microorganism, the desired production, and the nature of the material, with particular concern to its hydrophilicity and porosity.

Considering all of that, a second order factorial design was done, as described in Materials and Methods, to better investigate the effect of these two operational variables on $\mathrm{CA}$ production. The best inoculum concentration $\left(0.5 \cdot 10^{6}\right.$ spores/g dry orange peel) was applied, and the time of incubation was fixed at $62 \mathrm{~h}$ to avoid possible substrate limitations under some of the tested conditions.

As a result, the following significant model (Table 3), expressed in codified values, was obtained:

$$
\mathrm{CA}(\mathrm{mg} / \mathrm{g})=92.0-5.5 \mathrm{~W}-19.0 \mathrm{~B}-9.0 \mathrm{~W}^{2}+7.1 \mathrm{~B}^{2},[1]
$$


whose response surface within the experimental domain is illustrated in Fig. 3.

The absolute values of the coefficients of the equation, representing $44 \%$ of the absolute value of the independent term, confirm, first of all, the strong effect of these two operating variables considered. The maximum predicted response (133.8 $\mathrm{mg} \mathrm{CA} / \mathrm{g})$, corresponding to codified values of $\mathrm{W}=-0.305$ and $\mathrm{B}=-1.414$ and natural values of $\mathrm{W}=70 \%$ of saturation and $\mathrm{B}=1 \mathrm{~g} / \mathrm{flask}$, was in fact 2.5 -fold the minimum predicted one $(53.5 \mathrm{mg} \mathrm{CA} / \mathrm{g})$.

Table 3. Experimental results and analysis of variance of the model describing the effect of the water content (W) and the bed loading (B) on SSF citric acid (CA) production by A. niger on orange peels. (SS: sum of squares, FD: freedom degrees, QM: mean squares).

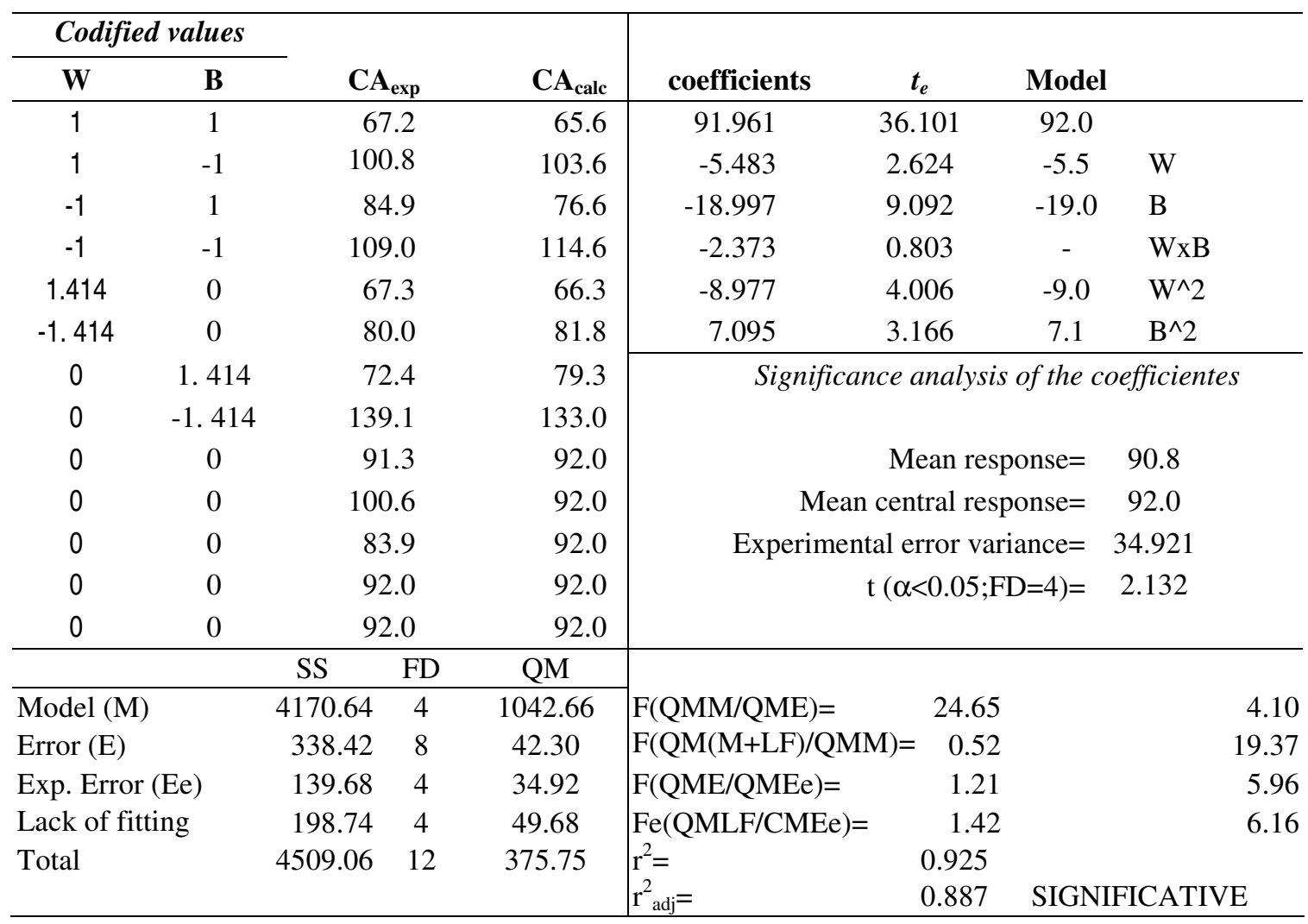

Considering now the behaviour of these two variables inside the experimental domain (Fig. 3), it is possible to make a mechanistic interpretation of the model in terms of the real variables: aeration and water activity $\left(\mathrm{a}_{\mathrm{w}}\right)$. The convex profile of the CA response surface with regard to $\mathrm{W}$, with a maximum inside the domain, reflects the need of increasing the amount of water to improve $\mathrm{a}_{\mathrm{w}}$ and, consequently, fungal metabolism and nutrients diffusion. From this maximum threshold, aeration restrictions become relevant as a consequence of the decrease of the substrate porosity and the interparticular void space.

With respect to $\mathrm{B}$, and taking into account the influence of this operating variable on gas transfer, the high value of the first order B term indicates the very important effect of aeration on this system and reduces the relative importance of the quadratic term. 


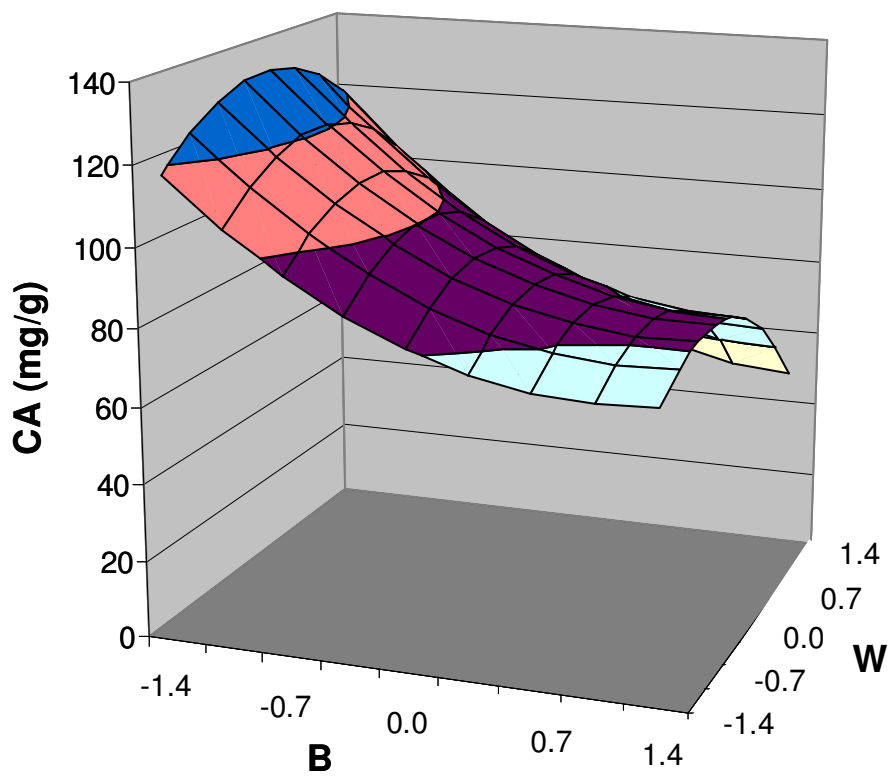

Figure 3. Response surface obtained from equation [1], showing the effect of the bed loading (B) and the water content (W) of the solid on the citric acid (CA) production from orange peel by SSF.

\section{Water addition during incubation}

Although the model allowed enhancing CA production at $62 \mathrm{~h}$ of incubation, at this time there were still sugars remaining that could lead to higher levels of CA if the culture were continued until substrate depletion. When thinking about prolonging the time of incubation in solid state cultures, it must be taken into account that water activity can decrease as a consequence of water evaporation and consumption by the fungus metabolism, and reach low and harmful levels. As a consequence, the optimum $\mathrm{W}$ value defined by the model for $62 \mathrm{~h}$ of incubation could not be directly extrapolable to longer times.

To allow the incubation to continue without water limitations in order to consume the substrate and increase CA production, it seemed necessary to supply water along the culture without affecting negatively the aeration by an excess of the liquid. Consequently, 4 fermentations were performed starting at the best conditions defined by the model $(\mathrm{W}=70 \%$ of saturation and $\mathrm{B}=1 \mathrm{~g} /$ flask) and adding water in different proportions and rates, as specified in the Materials and Methods section, whose results, in terms of CA production, are illustrated in Fig. 4.

The highest CA production (193.2 mg CA/g dry) was obtained at $86 \mathrm{~h}$ of incubation adding water every $12 \mathrm{~h}$ starting from $62 \mathrm{~h}$ (run D), a value $17 \%$ higher than that obtained in the reference run (A). Moreover, it is interesting to highlight that, in spite of the negative effect at $62 \mathrm{~h}$ on CA production expected in series $\mathrm{C}$ by the use of $\mathrm{W}$ values higher than the optimum predicted by the model, the productions of run $\mathrm{C}$ and $\mathrm{D}$ at $86 \mathrm{~h}$ were practically coincident, as the likely consequence of excess water evaporation at this time. However, run B was the worst one ever, probably due to an excess of water at $62 \mathrm{~h}$ and to an insufficient water content at longer incubation times. These results strongly suggest the need of adding water progressively along the SSF and then controlling carefully the maintenance of adequate $\mathrm{a}_{\mathrm{w}}$ and aeration. 


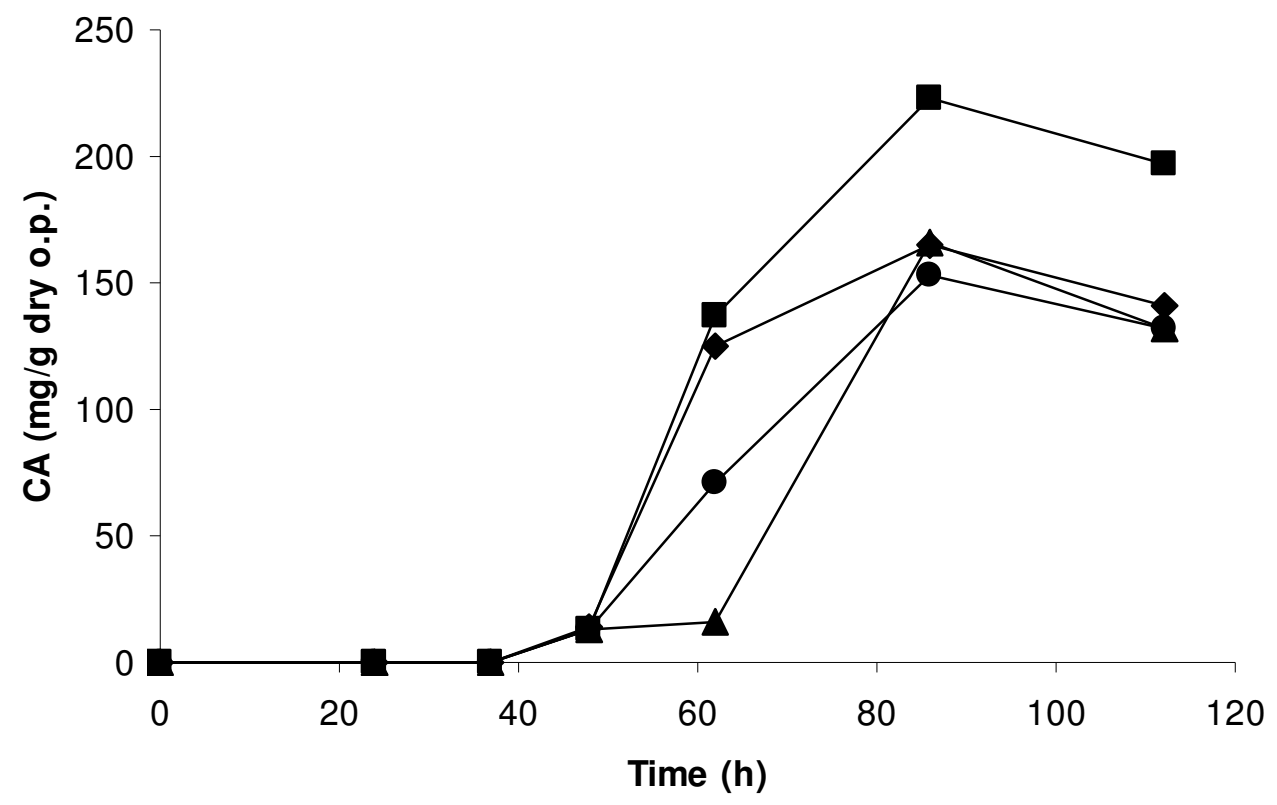

Figure 4. Evolution of CA throughout SSF after water addition: A) control without addition of water ( $\square$ ); B) addition of 0.08 $\mathrm{mL} /$ flask every $12 \mathrm{~h}$ starting from $48 \mathrm{~h}(\bullet)$; C) addition of $0.12 \mathrm{~mL} /$ flask every $12 \mathrm{~h}$ starting from $48 \mathrm{~h}(\mathbf{\Delta})$; and D) addition of $0.12 \mathrm{~mL} /$ flask every $12 \mathrm{~h}$ starting from $62 \mathrm{~h} \mathrm{(} \mathbf{(})$. Results are the average of three independent experiments. Standard deviations were below $2.1 \%$ of the mean value.

Effect of methanol (MeOH) addition on citric acid production by SSF

The addition of methanol at low concentrations can improve the yield of citric acid in cultures of $A$. niger, although contradictory effects have been reported. For example, Zhang (59) added $2 \% \mathrm{MeOH}$ to the solid residue of an orange juice factory in fermentations carried out by A. niger 999. Meanwhile, Kang et al. (24) found the optimal conditions in terms of maximum yield of citric acid $(80.4 \%)$ from skins of mandarin by $A$. niger, using semisolid fermentations, with the addition of $0.2 \% \mathrm{NH}_{4} \mathrm{NO}_{3}, 0.1 \%$ of $\mathrm{MgSO}_{4} \cdot 7 \mathrm{H}_{2} \mathrm{O}, 2.5 \%$ $\mathrm{MeOH}$ or $1.5 \%$ of ethanol. Tran et al. (52), obtained the highest CA yield (194 g/kg) adding $3 \%$ methanol and 5 ppm de $\mathrm{Fe}^{2+}$ during fermentations conducted using pineapple waste and A. niger ACM 4992. De Lima et al. (11) added $4 \%$ methanol using A. niger ATCC 1015 and pineapple waste in solid-state fermentation to achieve the highest CA production
(132 g/kg). Recently, Rodrigues et al. (43) obtained the best results (445.4 $\mathrm{g}$ of $\mathrm{CA} / \mathrm{kg}$ of citric pulp) with sugarcane molasses and $4 \%$ methanol (v/w) in SSF by A. niger LPB BC mutant. Finally, Roukas (44) reported that the addition of $6 \%$ (w/w) methanol into the substrate increased the concentration of citric acid from 176 to $264 \mathrm{~g} / \mathrm{Kg}$ dry pod during SSF. The same stimulatory effect of methanol was observed by Kumar et al. (30) using a mixture of different fruit wastes and bagasse in SSF by A. niger DS1. Conversely, some authors have reported a decreased synthesis of CA after methanol addition. For instance, Hang et al. (17) observed that the supplementation of $0.74 \mathrm{mmol}$ methanol/L diminishes the $\mathrm{CA}$ production during the SSF of kiwifruit peel by A. niger ATCC 9142, and Tsay and To (54) reported that methanol inhibited mycelial growth of A. niger TMB 2022 as well as CA production. Similar findings were reported by Navaratnam et al. (37), Ali et al. (3) and Xie and West (58). 
In a previous study, Rivas et al. (42), adding $4 \%$ (v/w) methanol to an orange peel aqueous extract as culture medium, increased 20-fold the maximum CA production with the same strain of Aspegillus niger in submerged fermentation, although this was accompanied by an increase in the duration of the lag phase. To study the possibility of improving the production also in this system, four fermentations were done in the presence of methanol under the best conditions previously defined by the model, with water addition according to the protocol earlier defined for run $\mathrm{D}$. To this purpose, methanol was added at the beginning of the incubation and after sterilization in proportions $(0,2,4$, and $6 \% \mathrm{v} / \mathrm{w})$ usually applied in submerged and solid state cultures (18, 43). Nevertheless, in all the cases methanol had a negative effect on the cultivation, leading not only to an increase in the lag time, but also to a strong decrease in the maximum CA production for fermentations with $4 \%$ and $6 \%$ (v/w) methanol.

These results suggest that the positive effects attributed to methanol due to the reduction of the toxicity of some metal ions, the positive alteration of the cell wall and the membrane, and the modification of the fungal morphology (23), are not relevant in this system. The intrinsic effect of the conditions defined by the solid state culture system on fungal morphology and metabolism could explain the lack of an important favorable effect of methanol on CA production in this case. On the other hand, the low values of $a_{w}$ that usually characterize the solid state cultures performed with low water contents and hydrophilic supports as orange peel, could have emphasized the methanol toxicity as a consequence of a high local methanol activity.

\section{Comparison between SSF and submerged culture for CA production}

Recently, there have been an increasing number of reports on the use of SSF processes because they exhibit a series of advantages over submerged fermentations. Since the culture conditions are more similar to the natural habitat of filamentous fungi, these are in fact able to grow and excrete large amounts of hydrolytic enzymes and, consequently, product concentrations after extractions are usually higher, and the amounts of liquid and solid wastes generated are lower (16, 17, 30). Furthermore, in SSF the degree of aeration is higher, the low water activity reduces the risk of bacterial contaminations, and the energy requirements are lower. On the other hand, SSF also shows some disadvantages such as a greater challenge for control of some important operating variables such as $\mathrm{pH}$ and temperature.

In a previous work, Rivas et al. (42) submitted orange peel to autohydrolysis at $130{ }^{\circ} \mathrm{C}$ at liquid/solid ratio of $8.0 \mathrm{~g} / \mathrm{g}$. Without additional nutrients, $40 \mathrm{~g}$ of the liquors generated were employed as media for submerged CA production by A. niger in $100 \mathrm{~mL}$-Erlenmeyer flasks at $30^{\circ} \mathrm{C}$ and $200 \mathrm{rpm}$. Table 4 allows comparing the results of the best fermentations of dry orange peel in terms of CA produced by the same strain in submerged fermentation (in the presence of $40 \mathrm{~mL} / \mathrm{kg}$ methanol and $20 \mathrm{~g} / \mathrm{L}$ calcium carbonate) and in $\mathrm{SSF}(\mathrm{W}=70$ $\% ; \mathrm{B}=1 \mathrm{~g}$; addition of $0.12 \mathrm{~mL} \mathrm{H}_{2} \mathrm{O} /$ Erlenmeyer flask every $12 \mathrm{~h}$ starting from $62 \mathrm{~h}$ ). All the data refer to the time of the highest $\mathrm{CA}$ concentration in each fermentation. The first remarkable differences between these two culture systems were the different state of the substrate and the sugar availability, which made unavoidable the use of different units. Nevertheless, to make easier the comparison between them, the concentrations of sugars and CA in the submerged culture were expressed as mg per $g$ of dry orange peel considering the earlymentioned $8.0 \mathrm{~g} / \mathrm{g}$ water/solid ratio employed for preparing the extract. All the sugars contained in the solid substrate were available for SSF, whereas only those solubilized by autohydrolysis were so for the submerged fermentation. Thus, sucrose was the most abundant sugar in the SSF and fructose in the submerged one. It is also important to notice that the authoydrolysis led to more diluted fermentation media in comparison with SSF.

Another notable difference between the two methods 
concerned the time behavior of the concentrations of the different sugars. In both cases sucrose was the first sugar to disappear. However, while in submerged culture glucose and fructose were gradually consumed throughout the cultivation, the levels of monosaccharides in SSF increased slightly during sucrose depletion. Several species belonging to the genus Aspergillus are reported to hydrolyze extracellular sucrose to be used later as a carbon source in the form of glucose and fructose (13). These results suggest that the rate of sucrose hydrolysis was higher than that of consumption of the resulting monosaccharides, thus leading to their net accumulation at the beginning of cultivation in the case of the SSF.

The SSF and the submerged cultures also differed markedly in terms of the yield of CA per gram of dry orange peel, which reached a value in SSF (193.2 mg/g dry orange peel) about 3-fold that observed in submerged culture (73.6 $\mathrm{mg} / \mathrm{g}$ dry orange peel). In addition, it was comparable with those reported for dry carob pod (176 mg/g) (44) and higher than for kiwifruit peel (100 mg/g) (17), and dry fig (64 mg/g) (45).

On the other hand, the yields of CA referred to sugar consumption $\left(\mathrm{Y}_{T S c}=0.61\right.$ and $0.58 \mathrm{~g} / \mathrm{g}$ in SSF and submerged culture, respectively) were comparable for the two systems, suggesting that the metabolic dysfunctions responsible for CA accumulation were ensured to the same extent in both culture modalities. However, the potential of SSF is highlighted by the fact that no methanol is required to stimulate $\mathrm{CA}$ production as for the submerged culture (42). This seems to be confirmed by the values of the yield referred only to the neutral sugars available at the beginning. This parameter was in fact substantially lower in submerged culture $\left(\mathrm{Y}_{T S o}=0.32 \mathrm{~g} / \mathrm{g}\right)$ than in $\operatorname{SSF}\left(\mathrm{Y}_{T S o}=0.59 \mathrm{~g} / \mathrm{g}\right)$, likely due to the interruption of CA production when sugars were not yet completely consumed.

Table 4. Comparison of the main results of submerged fermentation and SSF of dry orange peel by A. niger.

\begin{tabular}{lcc}
\hline Reference & $\begin{array}{c}\text { Submerged culture }(\mathbf{g} / \mathbf{L}) \\
\text { Rivas } \text { et al., } \mathbf{~ 2 0 0 8}\end{array}$ & $\begin{array}{c}\text { SSF }(\mathbf{m g} / \mathbf{g}) \\
\text { This work }\end{array}$ \\
\hline Initial sucrose & 6.6 & 156.6 \\
Initial glucose & 9.6 & 137.3 \\
Initial fructose & 13.6 & 145.2 \\
$\mathrm{TS}_{0}$ & 29.8 & 439.1 \\
Residual sucrose & 0.0 & 0.0 \\
Residual glucose & 4.1 & 7.6 \\
Residual fructose & 8.3 & 0.0 \\
Total residual sugars & 12.4 & 7.6 \\
$\mathrm{TS}_{\mathrm{c}}$ & 17.4 & 431.5 \\
CaCO $_{3}$ & 20 & - \\
Methanol $_{\text {Fermentation time }(\mathrm{h})}$ & 40 & - \\
Citric acid & 72 & 85 \\
$\mathrm{Y}_{T S c}\left(\mathrm{~g}\right.$ citric acid/g $\left.\mathrm{TS}_{\mathrm{c}}\right)$ & 9.2 & 223.2 \\
$\mathrm{Y}_{T S o}\left(\mathrm{~g}\right.$ citric acid/g $\left.\mathrm{TS}_{0}\right)$ & 0.53 & 0.52 \\
\hline $\mathrm{TS}$ & 0.31 & 0.51 \\
\hline
\end{tabular}

$\mathrm{TS}_{0}=$ Total initial neutral sugars.

$\mathrm{TS}_{\mathrm{C}}=$ Total consumed neutral sugars.

$\mathrm{Y}=$ Yield of CA on the initial amount of dry orange peel.

$\mathrm{Y}_{T S o}=$ Yield of $\mathrm{CA}$ on $\mathrm{TS}_{0}$.

$\mathrm{Y}_{T S c}=$ Yield of CA on $\mathrm{TS}_{\mathrm{c}}$.

$\mathrm{Y}_{\max }=$ Experimental conversion of neutral sugars to CA with respect to the theoretical yield (one CA mol per

mol of glucose or fructose consumed; two CA moles per mol of sucrose consumed). 


\section{CONCLUSIONS}

The results of this study point out the viability of Valencia orange (Citrus sinensis) peels as substrate for the production of citric acid (CA) by Aspergillus niger CECT-2090 in solid-state fermentation (SSF). Compared to previous results obtained in submerged culture, the SSF proved to be very versatile and did not need any additional nutrients or treatment besides sterilization. The highest CA concentration $(193.2 \mathrm{mg} / \mathrm{g}$ dry orange peel) was obtained at $85 \mathrm{~h}$ of incubation using an inoculum concentration of $0.5 \cdot 10^{6}$ spores/g of dry orange peel, a bed loading of $1.0 \mathrm{~g} /$ Erlenmeyer, an initial water content of $2.52 \mathrm{~mL} / \mathrm{g}$ of orange peel, corresponding to a $70 \%$ saturation, and a water addition of $0.12 \mathrm{~mL} \mathrm{H}_{2} \mathrm{O} /$ Erlenmeyer flask every $12 \mathrm{~h}$ starting from $62 \mathrm{~h}$. Methanol addition did not show to improve CA production. During SSF the microorganism likely produced pectinases, but pectins were not metabolized in any appreciable extent. Finally, SSF ensured yields of product on total initial sugars and consumed sugars of $0.59 \mathrm{~g} \mathrm{CA} / \mathrm{g} \mathrm{TS}$ and $0.61 \mathrm{~g} \mathrm{CA} / \mathrm{g} \mathrm{TS}_{\mathrm{C}}$, respectively. These results are considerably better than those previously obtained in submerged culture.

\section{ACKNOWLEDGMENTS}

We are grateful to the Spanish Government (project CT Q2006-02241/PPQ), which partially financed this work through the FEDER funds of the European Union, the FPI grant to Belén Max and the MAEC-AECID grant to Belinda P. Bibbins.

\section{REFERENCES}

1. Adham, N.Z. (2002). Attempts at improving citric acid fermentation by Aspergillus niger in beet-molasses. Bioresour. Technol. 84(1), 97-100.

2. Akhnazarova, S.; Kafarov, V. (1982). In: Experiment Optimization in Chemistry and Chemical Engineering, Mir, Moscow, Russia.

3. Ali, S.; Ashraf, H.; Ikram, U. (2002). Enhancement in citrate production by alcoholic limitation. J. Biol. Sci. 2, 70-72.
4. Anastasssiadis, S.; Morgunov, I.G.; Kamzolova, S.V.; Finogenova, T.V. (2008). Citric acid production patent review. Recent. Pat. Biotechnol. 2, 107-123.

5. Aravantinos-Zafiris, G.; Tzia, C.; Oreopoulou, V.; Thomopoulos, C.D. (1994). Fermentation of orange processing wastes for citric acid production. J. Sci. Food Agric. 65, 117-120.

6. Babu, I.S.; Rao, G.H. (2006). Citric acid production by Yarrowia lipolytica NCIM 3589 in solid state fermentation using pineapple waste as a novel substrate. Asian J. Microbiol. Biotechnol. Environ. Sci. 8(4), 799-802.

7. Box, G.E.P.; Hunter, W.G.; Hunter, J.S. (1989). In: Estadística para Investigadores, Reverté, Barcelona, Spain.

8. Cannel, E.; Moo-Young, M. (1980). Solid-state fermentation systems. Process Biochem. 15(6), 24-8.

9. Castilho, L.R.; Medronho, R.A.; Alves, T.L.M. (2000). Production and extraction of pectinases obtained by solid state fermentation of agroindustrial residues with Aspergillus niger. Bioresour. Technol. 71(1), 45-50.

10. De Gregorio, A.; Mandalari, G.; Arena, N.; Nucita, F.; Tripodo, M.M.; Lo Curto, R.B. (2002). SCP and crude pectinase production by slurrystate fermentation of lemon pulps. Bioresour. Technol. 83(2), 89-94.

11. de Lima, V.L.A.G.; Stamford, T.L.M.; Salgueiro, A.A. (1995). Citric acid production from pineapple waste by solid-state fermentation using Aspergillus niger, Arquivos de Biologia e Tecnologia 38(3), 773-783.

12. Flores, J.L.; Gutiérrez-Correa, M.; Tengerdy, R.P. (1994). Citric acid production by solid state fermentation of prickly pear peel with Aspergillus niger. Agro-Food-Industry Hi-Tech 5(1), 18-20.

13. Friedrich, J.; Cinierman, A.; Steiner, W. (1994). Concomitant biosynthesis of Aspergillus niger pectolytic enzymes and citric acid on sucrose. Enzyme Microb. Technol. 16(8), 703-707.

14. Ghildyal, N.P.; Ramakrishna, M.; Lonsane, B.K.; Karanth, N.G. (1992). Gaseous concentration gradients in tray type solid state fermentors. Effect on yields and productivities. Bioproc. Eng. 8(1-2), 67-72.

15. Grohmann, K.; Baldwin, E.A. (1992). Hydrolysis of orange peel with pectinase and cellulase enzymes. Biotechnol. Lett. 14, 1169-1174.

16. Grohmann, K.; Cameron, R.G.; Buslig, B.S. (1995). Fractionation and pretreatment of orange peel by dilute acid hydrolysis. Bioresour. Technol. $54,129-141$.

17. Hang, Y.D.; Luh, B.S.; Woodams, E.E. (1987). Microbial production of citric acid by solid state fermentation of kiwifruit peel. J. Food Sci. 52, 226-227.

18. Hang, Y.D.; Woodams, E.E. (1986). Solid-state fermentation of apple pomace for citric acid production, MIRCEN J. Appl. Microbiol. Biotechnol. 2(2), 283-287.

19. Hang, Y.D.; Woodams, E.E. (1986). Utilization of grape pomace for citric acid production by solid-state fermentation. Am. J. Enol. Vitic. 
37(2), 141-2.

20. Hang, Y.D.; Woodams, E.E. (1989). A process for leaching citric acid from apple pomace fermented with Aspergillus niger in solid-state culture. MIRCEN J. Appl. Microbiol. Biotechnol. 5(3), 379-82.

21. Harvey, E.M.; Rygg, G.L.J. (1936). Physiological changes in the rind of California oranges during growth and storage. J. Agric. Food Chem. 52, 723-46.

22. Imandi, S.B.; Bandaru, V.V.R.; Somalanka, S.R.; Bandaru, S.R.; Garapati, H.R. (2008). Application of statistical experimental designs for the optimization of medium constituents for the production of citric acid from pineapple waste. Bioresour. Technol. 99(10), 4445-4450.

23. Ingram, L.O.; Buttke, T.M. (1984). Effects of alcohols on microorganisms. In: Advances in Microbial Physiology 25, Academic Press, London, UK, pp. 253-300.

24. Kang, S.K.; Park, H.H.; Lee, J.H.; Lee, Y.S.; Kwon, I.B.; Sung, N.K. (1989). Citric acid fermentation from mandarin orange peel by Aspergillus niger, Sanop Misaengmul Hakhoechi 17, 510-518.

25. Kapoor, K.K.; Chaudhary, K.; Tauro, P. (1982). Prescott and Dunn's Industrial Microbiology, $4^{\text {th }}$ edn. G. Reed (Ed), AVI Publishing Co, Wesrport, CT.

26. Kesterson, J.W.; Braddock, R.J. (1976). By-products and specialty products of Florida citrus, Bull. Agric. Experiment State (Florida), pp. 784 1-119.

27. Khare, S.K.; Jha, K.; Gandhi, A.P. (1996). Citric acid production from okara (soy-residue) by solid-state fermentation. Bioresour. Technol. 54(3), 323-5.

28. Kubicek, C.P. (2001). Organic acids, In: C.R. Ratledge, B. Kristiansen (eds), Basic Biotech. Cambridge University Press, Cambridge, pp. 305324.

29. Kumar, A.; Jain, V.K. (2008). Solid state fermentation studies of citric acid production, Afri. J. Biotechnology 7(5), 644-650.

30. Kumar, D.; Jain, V.K.; Shanker, G.; Srivastava, A. (2003). Citric acid production by solid state fermentation using sugarcane bagasse. Process Biochem. 38(12), 1731-1738

31. Lotfy, W.A.; Ghanem, K.M.; El-Helow, E.R. (2007). Citric acid production by a novel Aspergillus niger isolate: I. Mutagenesis and cost reduction studies. Bioresour. Technol. 98, 3464-3469.

32. Lu, M.; Brooks, J.D.; Maddox, I.S. (1997). Citric acid production by solid-state fermentation in a packed-bed reactor using Aspergillus niger. Enzyme Microb. Tech. 21, 392-397.

33. Ma, E.; Cervera, Q.; Mejía Sánchez, G.M. (1993). Integrated utilization of orange peel. Bioresour. Technol. 44, 61-63.

34. Maldonado, M.C.; Strasser De Saad, A.M. (1998). Production of pectinesterase and polygalacturonase by Aspergillus niger in submerged and solid state systems. J. Ind. Microbiol. Biotechnol. 20(1), 34-38.

35. Murado, M.A., González, M.P.; Torrado, A.; Pastrana, L.P. (1997). Amylase production by solid state culture of Aspergillus oryzae on polyurethane foams. Some mechanistic approaches from an empirical model. Process Biochem. 32(1), 35-42.

36. Narayanamurthy, G.; Ramachandra, Y.L., Rai, S.P.; Ganapathy, P.S.S.; Kavitha, B.T.; Manohara, Y.N. (2008). Comparative studies on submerged, liquid surface and solid state fermentation for citric acid production by Aspergillus niger RCNM17. Asian J. Microbiol. Biotechnol. Environ. Sci. 10, 361-364.

37. Navaratnam, P.; Arasaratnam, V.; Balasubramaniam, K. (1998). Channelling of glucose by methanol for citric acid production from Aspergillus niger. World J. Microbiol. Biotechnol. 14(4), 559-563.

38. Prado, F.C.; Vandenberghe, L.P.S.; Woiciechowski, A.L.; RodriguesLeon, J.A.; Soccol, C.R. (2005). Citric acid production by solid - state fermentation on a semi-pilot scale using different percentages of treated cassava bagasse. Braz. J. Chem. Eng. 22(4), 547-555.

39. Raimbault, M.; Alazard, D. (1980). Culture method to study fungal growth in solid state fermentation. Eur. J. Appl. Microbiol. Biotechnol. 9, 199-209.

40. Ramachandran, S. ; Fontanille, P. ; Pandey, A. ; Larroche. C. (2006). Gluconic Acid: Properties, Applications and Microbial Production. Food Technol. Biotechnol. 44(2), 185-195.

41. Ramana Murthy, M.V.; Karanth, N.G.; Raghava Rao, K.S.M.S. (1993). Biochemical engineering aspects of solid-state fermentation. Adv. Appl. Microbiol. 38, 99-147.

42. Rivas, B.; Torrado, A.; Torre, P.; Converti, A.; Domínguez, J.M. (2008). Submerged citric acid fermentation on orange peel autohydrolysate. $J$. Agric. Food Chem. 56, 2380-2387.

43. Rodrigues, C.; Porto de Souza Vandenberghe, L.; Teodoro, J.; Pandey, A.; Zoclo, C.R. (2009). Improvement on citric acid production in solidstate fermentation by Aspergillus niger LPB BC mutant using citric pulp. Appl. Biochem. Biotechnol. 158(1), 72-87.

44. Roukas, T. (1998). Citric acid production from carob pod by solid-state fermentation. Enzyme Microb. Tech. 24 (1/2), 54-59.

45. Roukas, T. (2000). Citric and gluconic acid production from fig by Aspergillus niger using solid-state fermentation. J. Ind. Microbiol. Biot. 25(6), 298-304.

46. Selvi, V.; Kanna, K.S.; Banerjee, R.; Singh, G.; Ram, L.C. (2006). Citric acid production from sugarcane bagasse through solid state fermentation by mutants of Aspergillus niger. Asian J. Microbiol. Biotechnol. Environ. Sci. 8, 791-794.

47. Sinclair, W.B.; Crandall, P.R. (1953). Polyuronide fraction and soluble and insoluble carbohydrates of orange peel. Bot. Gaz. 115, 162-73.

48. Shojaosadati, S.A.; Babaeipour, V. (2002). Citric acid production from apple pomace in multi-layer packed bed solid-state bioreactor. Process Biochem. 37(8), 909-914.

49. Soccol, C.R.; Vandenberghe, L.P.S.; Rodrigues, C.; Pandey, A. (2006). New Perspectives for Citric Acid Production and Application. Food Technol. Biotechnol. 44, 141-149. 
50. Solís-Pereira, S.; Favela-Torres, E.; Viniegra-González, G.; GutierrezRojas, M. (1993). Effects of different carbon sources on the synthesis of pectinase by Aspergillus niger in submerged and solid state fermentations. Appl. Microbiol. Biotechnol. 39(1), 36-41.

51. Strickland, J.D.H.; Parsons, T.R. (1968). A Practical Handbook of Seawater Analysis. In: Fisheries Research Board of Canada, Queen's Printer, Ottawa, Ont., Canada, pp. 167-311.

52. Tran, C.T.; Sly, L.I.; Mitchell, D.A. (1998). Selection of a strain of Aspergillus for the production of citric acid from pineapple waste in solid-state fermentation. World J. Microb. Biot. 14(3), 399-404.

53. Tran, C.T.; Mitchell, D.A. (1995). Pineapple waste - a novel substrate for citric acid production by solid - state fermentation. Biotechnol. Lett. 17(10), 1107-10.

54. Tsay, S.S.; To, K.Y. (1987). Citric acid production using immobilized conidia of Aspergillus niger TMB 2022. Biotechnol. Bioeng. 19, 297-304.
55. Vandenberghe, L.P.S.; Soccol, C.R.; Prado, F.C.; Pandey, A. (2004). Comparison of citric acid production by solid-state fermentation in flask, column, tray, and drum bioreactors. Appl. Biochem. Biotech. 118(1-3), 293-303.

56. Wang, J.; Liu, P. (1996). Comparison of citric acid production by Aspergillus niger immobilized in gels and cryogels of polyacrylamide. $J$. Ind. Microbiol. 16, 351-353.

57. Wong, C.M.; Wong, K.H.; Chen, X.D. (2008). Glucose oxidase: natural occurrence, function, properties and industrial applications. Appl. Microbiol. Biotechnol. 78(6), 927-938.

58. Xie, G.; West. T.P. (2009). Citric acid production by Aspergillus niger ATCC 9142 from a treated ethanol fermentation co-product using solidstate fermentation. Lett. Appl. Microbiol. 48, 639-644.

59. Zhang, Q. (1988). Utilization of citrus wastes in production of citric acid. Shipin Kexue 104, 21-24. 